\title{
A Study of Relationship between Metacognition, Self-Confidence and Family Environment of 10+1 Students
}

\author{
Dr. Poornima Devi \\ Assistant Professor, C.R. College of Education, Hisar, Haryana (India)
}

\begin{abstract}
The present study was undertaken to investigate the relationship between metacognition, self-confidence and family environment of 10+1 students. The sample of the present study consisted of 800 students selected randomly from four districts of Haryana (India). Metacognition Inventory by Govil (2003), Self-confidence inventory by Agnihotri (1987) and Family Environment scale by Bhatia and Chadha (1993) were used. The findings indicate that there exists significant and positive relationship between metacognition, family environment and dimensions of family environment. On the other hand, significant but negative correlation between self-confidence and metacognition; self- confidence, family environment and dimensions of family environment is found.
\end{abstract}

KEYWORDS: Metacognition, Self Confidence, Family Environment, School Students

\section{INTRODUCTION}

Metacognition plays an important role in comprehension, memory, self-control, problem solving and personality development. A good metacognitive skills and positive knowledgeable environment might not work if a student or a person is not self-regulated and self-actualization. An information and technology-based society requires individuals, who are able to think critically about complex issues, analyse and adapt to new situations, solve problems of various kinds and communicate their thinking effectively. Thus, there is a need to make systematic educational efforts primarily aimed at influencing attitudes, behaviour, values and personality of individuals to manage their growth and development well. Laible and Carlo (2004) suggested that family is the environment where the children learned to use, understand and cope with the physical world. In the family, children get an education, learn lifetime values, norms, beliefs and obtain the power needed to become personalities.

\section{Metacognition}

Metacognition is the process of "thinking about thinking" and knowing "what we know" and "what we don't know." It refers to higher order mental processes involved in learning, such as making plans for learning, using appropriate skills and strategies to solve a problem, making estimates of performance and calibrating the extent of learning. It consists of two basic processes occurring simultaneously: monitoring one's progress as one learns and making changes and adapting one's strategies if one perceives one is not doing so well (Winn and Synder, 1996). The term metacognition refers to the psychological processes that are involved in the way a person controls, modifies, and appraises his own thoughts (Kaur, 2010). "Metacognition and reflection both are concerned with the process of monitoring, regulating and controlling an individual's thinking about their thinking” (Daniels, 2002).

\section{Self-Confidence}

Self-Confidence refers to a person's perceived ability to tackle situations successfully without leaning on others and to have a positive self-evaluation (Agnihotri, 1987). Self-confidence is the conviction that one is generally capable of producing desired results. Selfconfidence is the one thing that is much more important than any other abilities and traits. Self-confidence integrates the powers of mind and body and focuses them towards the goal.

Lack of confidence is not necessarily permanent but it can be if it is not addressed. Confident people have faith in their future and can accurately assess their capabilities (Goel \& Aggarwal, 2012). Self- confidence refers to a person's expectation of his or her ability to achieve a goal in a given situation and is a very influential factor in ensuring a person's potential is realized (Stevens, 2005).

\section{Family Environment}

Family is an enduring association of parent and offspring whose primary function are the socialization of the child and satisfaction of the members. "The family is the only socially recognized relation for child bearing and the essential agency for child rearing, 


\section{International Journal of Current Science Research and Review}

ISSN: 2581-8341

Volume 04 Issue 06 June 2021

DOI: 10.47191/ijcsrr/V4-i6-16, Impact Factor: 5.825

IJCSRR@ 2021

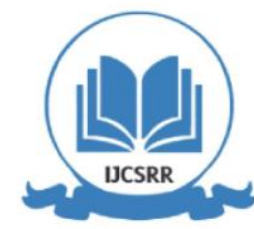

Www.ijcsrr.org

socialization, and introducing the child to the culture of the society, thereby shaping the basic character structure of our culture and forming the child's personality" (Frank, 1948).

Family environment refers to the climate prevailing in the home, which varies from culture to culture, society to society, family to family. The family environment possesses a certain consistency so that the impact of the same basic values, individuals, material objects etc., is felt over and over. Parental influence may not be felt in a specific situation, but the attitudes and ideas expressed day after day inevitably leave their mark (Bhatia \& Chadha, 1993).

There are three dimensions in the family environment scale used in the present study: Relationship Dimensions, Personal Growth dimensions and System Maintenance Dimensions.

\section{REVIEW OF RELATED LITERATURE}

Landline and Stewart (1998) studied relationship between metacognition, motivation, locus of control, self-efficacy and academic achievement and found that there exists significant positive relationship between metacognition, locus of control, self-efficacy and academic achievement. Kaur, Rana \& Kaur (2009) made an attempt to explore academic achievement and home environment as correlates of self-concept. The results of the study revealed self-concept to be positively correlated with academic achievement, though not significantly so. A significantly positive relationship of home environment components of protectiveness, conformity, reward, and nurturance with self-concept is revealed, there by meaning that use of rewards and nurturance from parents should be done for positive self-concept development among adolescents. However, the correlation of social isolation, deprivation of privileges and rejection components of home environment is significantly negative with self-concept among adolescents indicating that for positive self-concept development among adolescents, there should be less or no use of social isolation, deprivation of privileges and rejection. Kleitman \& Gibson (2011) does a study on metacognitive beliefs, self - confidence and primary learning environment of sixth grade students and found that academic self- efficacy and metacognitive competency beliefs define a broad factor. Metacognitive beliefsserve as a key factor of self-confidence. Students with stronger metacognitive beliefs were less engaging in self- handicapping behaviours. Rani, R., \& Govil, P. (2013) does an attempt to study the impact of metacognition on the home environment and mental health of adolescents. Results revealed that both home environment and mental health showed positive and significant impact on metacognition. Rahman, Mahmood et.al (2018) aimed to determine the relationship between family functioning and self-concept in the process among the troubled youth in a rehabilitationcentre. The study showed that family functioning has a significant relationship with adolescent self-concept. The support and involvement of parents in a positive relation with the dimensions of control and parental involvement, and personal appreciation of girls is more in relation to support and parental controls. Bakhtiar \&Minarni (2019) studied the effect of child abuse by parents on adolescent self - confidence.The results of the study indicate that there is an influence of child abuse by parents on adolescent self - confidence. Based on the research results obtained with a negative direction with a regression coefficient, if child abuse by parents has increased the confidence tends to decrease. Zahra \& Saleem (2021) studied family cohesion and depression in adolescents: A mediating role of self-confidence and found significant positive association between family cohesion and self-confidence and a significant negative association of family cohesion and self- confidence with depression was found.

\section{OBJECTIVES OF THE STUDY}

(a) To find the relationship between metacognition and family environment of 10+1 students.

(b) To find the relationship between self-confidence and family environment of 10+1 students.

(c) To find the relationship between metacognition and self - confidence of 10+1 students.

(d) To find the relationship between metacognition and dimensions of family environment of 10+1 students.

(e) To find the relationship between self - confidence and dimensions of family environment of 10+1 students.

\section{HYPOTHESES OF THE STUDY}

Ho1 There exists no significant relationship between metacognition and family environment of $10+1$ students.

Ho2 There exists no significant relationship between self-confidence and family environment of 10+1 students.

Ho3 There exists no significant relationship between metacognition and self - confidence of $10+1$ students.

Ho4 There exists no significant relationship between metacognition and 'Relationship Dimension' of family environment of $10+1$ students. 


\section{International Journal of Current Science Research and Review}

ISSN: 2581-8341

Volume 04 Issue 06 June 2021

DOI: 10.47191/ijesrr/V4-i6-16, Impact Factor: 5.825

IJCSRR@ 2021

WWw.ijcsrr.org

Ho5 There exists no significant relationship between metacognition and 'Personal Growth Dimension' of family environment of $10+1$ students.

Ho6 There exists no significant relationship between metacognition and 'System Maintenance Dimension' of family environment of $10+1$ students.

Ho7 There exists no significant relationship between self - confidence and 'Relationship Dimension' of family environment of $10+1$ students.

Ho8 There exists no significant relationship between self - confidence and 'Personal Growth Dimension' of family environment of $10+1$ students.

Ho9 There exists no significant relationship between self - confidence and 'System Maintenance Dimension' of family environment of $10+1$ students.

\section{RESEARCH METHODOLOGY}

Variables

Metacognition, Self- Confidence, Family Environment

\section{Method}

In the present study descriptive survey method has been used. This method is useful in finding out the facts of the present situation in a most precise way. In this study the investigator enquired about the metacognition, self-confidence and family environment of $10+1$ students of senior secondary schools of Haryana Board of Secondary Education.

\section{Sample}

The present study was conducted among students studying in 10+1 in senior secondary schools of Haryana Board of School Education. Out of the total population, a sample of 800 students was selected using multi-stage and stratified random sampling technique.

\section{Tools of the Study}

The following tools were used to collect data for the present study:

(i) Metacognition inventory by Govil (2003).

(ii) Self-confidence inventory by Agnihotri (1987).

(iii) Family Environment scale by Bhatia and Chadha (1993)

\section{Statistical Techniques}

The statistical techniques used are Mean \& Pearson's Product Moment correlation.

\section{ANALYSIS AND INTERPRETATION OF THE DATA}

With an objective of finding out the significance of relationship between metacognition, self- confidence and family environment, Pearson's Product Moment Correlation was employed.

Table 1: Coefficient of correlation between Metacognition and Family Environment of 10+1 Students

\begin{tabular}{|l|l|l|l|l|}
\hline Sr. No. & Variable & N & Mean & Coefficient of Correlation \\
\hline 1 & Metacognition & 800 & 85.86 & $.369^{* *}$ \\
\hline 2 & Family Environment & 800 & 252.64 & \\
\hline
\end{tabular}

** Significant at the 0.01 level of significance

Table 2: Coefficient of correlation between Self - Confidence and Family Environment of 10+1 Students

\begin{tabular}{|l|l|l|l|l|}
\hline Sr. No. & Variable & N & Mean & Coefficient of Correlation \\
\hline 1 & Self - Confidence & 800 & 24.58 & $-.274^{* *}$ \\
\hline 2 & Family Environment & 800 & 252.64 & \\
\hline
\end{tabular}

** Significant at the 0.01 level of significance 


\section{International Journal of Current Science Research and Review}

ISSN: 2581-8341

Volume 04 Issue 06 June 2021

DOI: 10.47191/ijcsrr/V4-i6-16, Impact Factor: 5.825

IJCSRR@ 2021

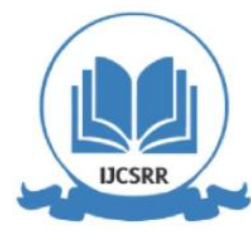

www.ijcsrr.org

Table 1 presents the coefficient of correlation between metacognition and family environment of $10+1$ students. The calculated value of coefficient of correlation is 0.369 which is significant at 0.01 levels of significance. It shows that metacognition and family environment of 10+1 students are positively and significantly related to each other. Thus, the hypothesis (H01) stating that "There exists no significant relationship between Metacognition and family environment of $10+1$ students" stands REJECTED at 0.01 level of significance.

Table 2 depicts the coefficient of correlation between self- confidence and family environment. The obtained value of coefficient of correlation is -0.274 which is significant at 0.01 level of significance. The result revealed significant and negative but very low relationship between self- confidence and family environment scores of 10+1 students. Thus, the hypothesis (H02) stating that "There exists no significant relationship between Self-Confidence and Family Environment of 10+1 students" stands REJECTED at 0.01 level of significance. The mean score of self-confidence shows average level of self - confidence as per manual.

Table 3: Coefficient of correlation between Metacognition and Self-Confidence of 10+1 Students

\begin{tabular}{|l|l|l|l|l|}
\hline Sr. No. & Variable & N & Mean & Coefficient of Correlation \\
\hline 1 & Metacognition & 800 & 85.86 & $-.176^{* *}$ \\
\hline 2 & Self - Confidence & 800 & 24.58 & \\
\hline
\end{tabular}

** Significant at the 0.01 level of significance

Table 4: Coefficient of correlation between Metacognition and 'Relationship dimensions' of Family Environment of $10+1$ Students

\begin{tabular}{|l|l|l|l|l|}
\hline Sr. No. & Variable & N & Mean & Coefficient of Correlation \\
\hline 1 & Metacognition & 800 & 85.86 & $.342^{* *}$ \\
\cline { 1 - 3 } & Relationship dimensions of Family Environment & 800 & 169.60 & \\
\hline
\end{tabular}

** Significant at the 0.01 level of significance

Table 3 shows the coefficient of correlation between metacognition and self - confidence of 10+1 students. The value of coefficient of correlation is found to be -.176 which is positive and significant at 0.01 level of significance. It shows that metacognition and self - confidence are related to each other. Thus, the hypothesis (H03) that "There exists no significant relationship between Metacognition and Self - Confidence of 10+1 students" stands REJECTED at 0.01 level of significance.

Table 4 indicates the coefficient of correlation between metacognition and relationship dimensions of family environment of $10+1$ students. The obtained value of coefficient of correlation is 0.342 which is significant at 0.01 level of significance. It shows that relationship dimensions of family environment and metacognition of 10+1 students are significantly and positively related to each other. Thus, the hypothesis (H04) stating "That there exists no significant relationship between Metacognition and Relationship Dimensions of Family Environment of 10+1 students" stands REJECTED at 0.01 level of significance.

Table 5: Coefficient of correlation between Metacognition and 'Personal Growth Dimensions' of Family Environment of 10+1 Students

\begin{tabular}{|l|l|l|l|l|}
\hline Sr. No. & Variable & N & Mean & Coefficient of Correlation \\
\hline 1 & Metacognition & 800 & 85.86 & $.301 * *$ \\
\cline { 1 - 3 } & Personal Growth dimensions of Family Environment & 800 & 59.72 & \\
\hline
\end{tabular}

** Significant at the 0.01 level of significance

Table 6: Coefficient of correlation between Metacognition and 'System Maintenance Dimensions' of Family Environment of 10+1 Students

\begin{tabular}{|l|l|l|l|l|}
\hline Sr. No. & Variable & N & Mean & Coefficient of Correlation \\
\hline 1 & Metacognition & 800 & 85.86 & $.285^{* *}$ \\
\cline { 1 - 3 } & System Maintenance dimensions of Family Environment & 800 & 23.33 & \\
\hline
\end{tabular}

** Significant at the 0.01 level of significance 


\section{International Journal of Current Science Research and Review}

ISSN: 2581-8341

Volume 04 Issue 06 June 2021

DOI: 10.47191/ijcsrr/V4-i6-16, Impact Factor: 5.825

IJCSRR@ 2021

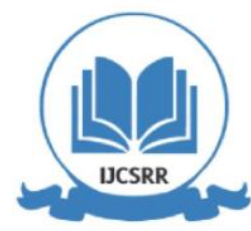

Www.ijcsrr.org

Table 5 shows the coefficient of correlation between metacognition and personal growth dimensions of family environment of $10+1$ students. The value of coefficient of correlation is found to be 0.301 which is significant at 0.01 level of significance. It shows that there is significant and positive relationship between personal growth dimension and metacognition of $10+1$ students. Thus, the hypothesis (H05) "That there exists no significant relationship between Metacognition and Personal Growth Dimensions of Family Environment of 10+1 students" stands REJECTED at 0.01 level of significance.

Table 6 indicates the coefficient of correlation between metacognition and system maintenance dimensions of family environment of $10+1$ students. The obtained value of coefficient of correlation is 0.285 which is significant at 0.01 level of significance. It shows that system maintenance dimensions and metacognition of 10+1 students are significantly and positively related to each other. Thus, the hypothesis (H06) stating that "There exists no significant relationship between Metacognition and System Maintenance Dimensions of Family Environment of 10+1 students" stands REJECTED at 0.01 level of significance.

Table 7: Coefficient of correlation between Self - Confidence and 'Relationship dimensions' of Family Environment of 10+1 Students

\begin{tabular}{|l|l|l|l|l|}
\hline Sr. No. & Variable & N & Mean & Coefficient of Correlation \\
\hline 1 & Self - Confidence & 800 & 24.58 & \multirow{2}{*}{$-.249 * *$} \\
\cline { 1 - 3 } & Relationship dimensions of Family Environment & 800 & 169.60 & \\
\hline
\end{tabular}

** Significant at the 0.01 level of significance

Table 8: Coefficient of correlation between Self - Confidence and 'Personal Growth Dimensions' of Family Environment of 10+1 Students

\begin{tabular}{|l|l|l|l|l|}
\hline Sr. No. & Variable & N & Mean & Coefficient of Correlation \\
\hline 1 & Self - Confidence & 800 & 24.58 & \multirow{2}{*}{$-.269 * *$} \\
\hline 2 & Personal Growth dimensions of Family Environment & 800 & 59.72 & \\
\hline
\end{tabular}

** Significant at the 0.01 level of significance

Table 9: Coefficient of correlation between Self - Confidence and 'System Maintenance Dimensions' of Family Environment of $10+1$ Students

\begin{tabular}{|l|l|l|l|l|}
\hline Sr. No. & Variable & N & Mean & Coefficient of Correlation \\
\hline 1 & Self - Confidence & 800 & 24.58 & \multirow{2}{*}{$-.150 * *$} \\
\cline { 1 - 3 } & System Maintenance dimensions of Family Environment & 800 & 23.33 & \\
\hline
\end{tabular}

** Significant at the 0.01 level of significance

Table 7 indicates the coefficient of correlation between self - confidence and relationship dimensions of family environment of 10+1 students. The obtained value of coefficient of correlation is -.249 which is significant at 0.01 level of significance. It shows that relationship dimensions of family environment and self - confidence of 10+1 students are significantly but negatively related to each other. Thus, the hypothesis (H07) stating "That there exists no significant relationship between Self - Confidence and Relationship Dimensions of Family Environment of 10+1 students" stands REJECTED at 0.01 level of significance.

Table 8 shows the coefficient of correlation between self - confidence and personal growth dimensions of family environment of $10+1$ students. The value of coefficient of correlation is found to be -.269 which is significant at 0.01 level of significance. It shows that there is significant and negative relationship between personal growth dimension and self - confidence of 10+1 students. Thus, the hypothesis (H08) "That there exists no significant relationship between Self - Confidence and Personal Growth Dimensions of Family Environment of 10+1 students" stands REJECTED at 0.01 level of significance.

Table 9 indicates the coefficient of correlation between self - confidence and system maintenance dimensions of family environment of $10+1$ students. The obtained value of coefficient of correlation is -.15 which is significant at 0.01 level of significance. It shows that system maintenance dimensions and self - confidence of 10+1 students are significantly and negatively related to each other. 


\section{International Journal of Current Science Research and Review}

ISSN: 2581-8341

Volume 04 Issue 06 June 2021

DOI: 10.47191/ijesrr/V4-i6-16, Impact Factor: 5.825

IJCSRR@ 2021

www.ijcsrr.org

Thus, the hypothesis (H09) stating that "There exists no significant relationship between Self - Confidence and System Maintenance Dimensions of Family Environment of 10+1 students" stands REJECTED at 0.01 level of significance.

\section{FINDINGS AND DISCUSSIONS}

The statistical data of the study reveals the following main findings:

- There exists significant and positive relationship between metacognition and family environment. It means appropriate family environment helps to develop higher order thinking skills among the students.

- There exists significant and negative but low relationship between self - confidence and family environment.

- There exists significant and negative relationship between metacognition and self - confidence.

- There exists significant and positive relationship between metacognition and relationship dimensions of family environment. It might be due to the fact that degree of commitment, help, and support of family members, freedom to express their feelings, less conflict in the family and unconditional acceptance help students to have higher order thinking.

- There exists significant and positive relationship between metacognition and personal growth dimensions of family environment of 10+1 students. It can be inferred from the result that independent decision making and participation in various social and recreational activities help an individual to take independent decisions.

- There exists significant and positive relationship between metacognition and system maintenance dimensions of family environment of $10+1$ students. The result leads to the inference that clear organization structure in planning family activities and responsibilities helps an individual to plan and organize their work

- There exists significant and negative relationship between self - confidence and relationship dimensions of family environment.

- There exists significant and negative relationship between self - confidence and personal growth dimensions of family environment of $10+1$ students.

- There exists significant and negative relationship between self - confidence and system maintenance dimensions of family environment of $10+1$ students.

\section{CONCLUSION}

From the above said findings we can conclude that there is positive and significant relationship between metacognition and family environment. Students who have better family environment have high metacognition than those who have inappropriate family environment. Self-confident students have belief in their abilities Significant and negative relationship between metacognition and self - confidence is found.Metacognition and various dimensions of family environment have positive and significant relationship which indicates that the students who have better family environment can do cognitive functions better than those who do not have appropriate family environment. It might be due to the fact that degree of commitment, help, and support of family members, freedom to express their feelings, less conflict in the family and unconditional acceptance help students to better evaluate their level of comprehension and understanding and have control on their thought processes.

\section{REFERENCES}

1. Laible D.J., Carlo G. (2004). The differential relations of maternal and paternal support and control to adolescents' social competence, self-work and sympathy. Journal of Adolescent's Research. 19,759-782.

2. Winn, W. \& Synder, D. (1996). Cognitive perspectives in psychology. In D.H. Jonnassen (Ed) Handbook of Research for Educational Communications and Technology (pp. 112-142). New York: Simon and Schuster Macmillan.

3. Kaur, Parvinder. (2010). A study of learning outcomes of adolescents in relation to their emotional intelligence, metacognition and personality traits. Chandigarh: Panjab University (Unpublished Ph.D. thesis).

4. Daniels, D. (2002). Metacognition and reflection. Retrieved from: http://edutechwiki.unige.ch/en/Metacognition

5. Agnihotri, Rekha (1987). Manual for Agnihotri's self-confidence inventory. Agra: National Psychological Corporation.

6. Goel, M. \& Aggarwal, P. (2012). A comparative study of self- confidence of single child and child with sibling. International Journal of Research in Social Sciences, 2(3), 89-98.

7. Stevens, T. G. (2005). Self-confidence. Retrieved from http://www.csulb.edu 


\section{International Journal of Current Science Research and Review}

ISSN: 2581-8341

Volume 04 Issue 06 June 2021

DOI: 10.47191/ijesrr/V4-i6-16, Impact Factor: 5.825

IJCSRR@ 2021

www.ijcsrr.org

8. Frank, L.K. (1948). What families do for the nation? American Journal of Sociology, 53, 471-473.

9. Bhatia, H. \& Chadha, N. K. (1993). Manual for Family Environment Scale (FES). Lucknow: Ankur Psychological Agency.

10. Landline, J. \& Stewart, J. (1998). Relationship between metacognition, motivation, locus of control, self efficacy and academic achievement. Canadian Journal of Counseling, 32(3), 200-212.

11. Kaur, J., Rana, J.S. \& Kaur, R. (2009). Home environment and academic achievement as correlates of self-concept among adolescents. Studies on Home and Community Science, 3(1), 13-17.

12. Kleitman, S., \& Gibson, J. (2011). Metacognitive beliefs, self-confidence and primary learning environment of sixth grade students. Learning and Individual Differences, 21(6), 728-735.

13. Rani, R., \& Govil, P. (2013). Metacognition and its correlates: a study. International Journal of Advancement in Education and Social Sciences, 1(1), 20-25.

14. Ab Rahman, Z., Mahmood, A. R., Long, A. S., Kamarzaman, M. H., Badaruddin, F., Ismail, I., ... \& Badaruzzaman, W. H. W. (2018). Family Environment and Confidence Consumption at the Center of Recovery. International Journal of Business and Social Science, 9(2).

15. Bakhtiar, H. S., \&Minarni, G. A. (2019). The effect of child abuse by parents on adolescent self confidence. International Journal of Scientific and Technology Research, 8(12), 3783-3788.

16. Zahra, S. T., \& Saleem, S. (2021). Family cohesion and depression in adolescents: A mediating role of selfconfidence. Journal of the Pakistan Medical Association, 71(2B), 677-680.

17. Govil, P. (2003). Manual for metacognition inventory. Agra: National Psychological Corporation.

Cite this Article: Poornima Devi (2021). A Study of Relationship between Metacognition, Self-Confidence and Family Environment of 10+1 Students. International Journal of Current Science Research and Review, 4(6), 610-616 